\title{
Analysis on Indoor Plant Landscapes in Interior Design Styles
}

\author{
Lei Xu \\ Academy of Fine Arts \\ Gannan Normal University \\ Ganzhou, China
}

\begin{abstract}
Today, with the advocating of the construction of the ecologically civilized city, indoor plant landscape as an interior design element is gradually becoming a fashion in modern social life. In this paper, the author has expounded the concept of indoor plant landscape, the functions of indoor ornamental plants and landscaping, and the design and application of plant landscapes in different interior design styles, making people have a basic understanding of indoor plant landscapes, and understand these dumb fairies. Under the designers' "magic"; in a world we can't see; plants have completed the work of purifying the air when they are breathing, and at the same time have embellished and perfected the interior design landscape; plants are silently creating a healthy, vibrant and natural indoor world for us.
\end{abstract}

Keywords-indoor plant landscape; interior space; interior design style; indoor plant; design

\section{INTRODUCTION}

In the new era of developed digital media, people are more and more pursuing the ecological environment; and are requiring the style of indoor living environment become more natural, such as the popular Zen space design, industrial style design, the rise of homestays, etc. It shows that people are paying more and more attention to the relationships between people and environment, people and health, environment and health, which has led to the integration of nature and interior.

This paper illustrates the concept, functions of indoor plant landscape and the application of indoor plant landscape in different interior design styles, illustrating the design characteristics, design personalities and strong plasticity of plants in the interior, opening up a new world for interior design.

\section{STATUS QUO}

In today's society where economic development and information transmission are rapid, high-rise buildings and high-tech products, as well as the interior decoration environment being paid more and more attention to, are making people have higher requirements for their material and spiritual life; but at the same time, they have blocked the connection between human and the natural environment and weakened the power of the natural environment: (1) they have caused changes in air quality and drinking water quality; (2) they have caused a sharp decline in people's physical functions.
The emergence of various diseases such as sub-health, airconditioning syndrome, and leukemia has made people realize the importance of "starting to work with the sunrise, going to rest with the sunset, and achieving harmony between human and nature"; people are beginning to realize the importance of the natural environment; realize the importance of creating a green living environment; realize that indoor design can be more ergonomic if implanted with natural plants. In this case, it is especially necessary to write the "indoor plant landscape in interior design style".

\section{THE CONCEPT OF INDOOR PLANT LANDSCAPE}

The indoor plant landscape is that people introduce natural plants into the living space, office space, commercial space, dining space, entertainment space and other architectural spaces, creating the environment with the main functions of rest, leisure, learning, communication, and sightseeing, as well as satisfying people's physiological and psychological needs. People will feel themselves in a tasteful, comfortable, beautiful, leisurely, and quiet environment, as if they are in nature.

Plants, as a living decorative material, are the most varied and cannot be replaced by any other decorative material, especially for indoor plants. In recent years, indoor plant landscaping has become more and more popular in interior design, especially in the design of commercial spaces, dining spaces, office spaces and living spaces. The flexible use of plant landscapes in interior design is inseparable from the functions and design effects of indoor plants.

\section{THE FUNCTIONS OF INDOOR PLANTS}

The rise of indoor plant landscapes has led to the continuous advancement of indoor plant cultivation techniques, making it possible for more and more plant species and plant landscapes to survive in indoor spaces, and at the same time more and more plant species and plant landscaping functions have been dug out by people:

\section{A. Practical Functions of Indoor Plants}

1) Purify air, lower the temperature and humidify the air: Bill Woiverton, an expert at NASA in the United States, said: "We have found that plants not only effectively remove toxic substances, but also have a strong transpiration effect, which is to release more water vapor into the environment." $\mathrm{He}$ 
believes this is the result of the "pump" effect of plants. When the plant "pumps" the water vapor, it also pulls the air into its root. Through this "breathing" process (inhalation of carbon dioxide, exhalation of oxygen), plants absorb the pollutants in the air and transport them to the roots, which are then swallowed and degraded by microorganisms, and finally the air is purified; at the same time plants can adjust indoor temperature and humidity, which are good for human's health.

2) Disinfection: Indoor plants can absorb a certain amount of harmful gases, such as sulfur dioxide, nitrogen dioxide, hydrogen fluoride, ammonia, chlorine, benzene, aldehydes, ozone, etc., playing a role in disinfection.

3) Promote physical and mental health: Indoor plants can increase negative ions in the air, and negative ions are free particles in the air. If there is enough energy to act on a molecule, such as a water molecule, the molecule will release an electron, and the electron combines with the nearby molecule to form an anion. The leaves of plants produce negative ions when they are releasing water vapor, and a large number of negative ions are needed for human's health.

\section{B. The Design Functions of Indoor Plants}

Indoor plants have the function of organizing space.

1) Plants have the function of guiding space: Plants can produce strong contrasts indoors, and they are usually very conspicuous. Therefore, in the design of indoor space, plant landscaping or potting can be used as the symbol of turning and for guiding space, which is both beautiful and decorative.

2) Plants have the function of delimiting space: Indoor plants are different from partition walls, partition boards and furniture partitions in the interior design of delimiting spaces. The indoor plant design has great flexibility. The delimited space has a certain degree of independence, yet is open and flexible.

3) Plants can be used as end views: At the beginning or at the end of the indoor space, in order to avoid the emptiness of space, plants can be used for simple landscaping or potting, which virtually separates the space and allows for an additional view of the attraction.

4) Plants have the function of embellishing space: In order to avoid the complexity of the design, on the empty wall, we only need to hang a flower, a potted plant, or a dead branch to activate the entire space.

5) Plants have the function of space transition: In the icy and angular interior space, the ad of the softness and color of plants can not only change the marginal effect of the facade but also enrich the level and extension of the space.

6) Plants have the function of dealing with corners of the space: In interior design, corners, pillars and other difficultto-handle corners are often encountered. In these places, some small plants can be placed or designed to brighten up space and avoid flaws.

\section{The Spatial Beautification Function of Indoor Plants}

1) Natural beauty of green plants: Using the natural beauty of green plants, including the color, shape, volume, and smell of plants, different contrasts in textures will be produced when the plants are combined with different interior design styles, so that the space can be beautified; as in the modern minimalist style, on the simple geometric wall, the hanging of vine plants can eliminate the monotony of the geometric space, making the wall vivid and not empty. The walls and plants complement each other and enhance the expressiveness and appeal of the indoor environment.

2) The pruning beauty of plants: Utilizing the pruning beauty of the plant, including the pruning state, shape and contour of the plant, make the plant complement the corresponding interior design style and make the plant and the design blend into one; as in the Zen-style space design, a potted individualized Podocarpus and the quiet Zen space can form a comfortable and harmonious space atmosphere.

3) The comprehensive beauty of plants: Using the comprehensive beauty of plants, including the integrated form, color and effect of natural and artificial combinations of plants, make them form colorful and ever-changing design spaces with different interior design styles; as in Southeast Asian style, bold decorative patterns and colors are combined with the art of flower arrangement and large-leaf potted plants to form a colorful exotic atmosphere, the interior space is formed without losing the elegance and order.

Indoor plants are part of the interior design. In indoor plant landscaping, as the center of the composition, they are often used as points, lines and faces in the decoration. Indoor plants can be as small as a few centimeters and as large as a few meters. In the landscaping design, it is necessary to coordinate the plant with the indoor space scale, and it is also necessary to closely relate the plant to the interior design style. Indoor plants, in the condition of satisfying their normal growth, coordinate the relationship between people, buildings, and indoor environment, and at the same time enable people to enjoy a comfortable and peaceful indoor environment, while dispelling and regulating people's tiredness and nervousness coming from their long-term staying in "hard space". Therefore, the design requirements of indoor plant landscapes in different interior design styles are especially important for interior designers.

\section{THE DESIGN OF PLANT LANDSCAPE IN DIFFERENT INTERIOR DESIGN STYLES}

\section{A. Modern Minimalist Style - the Design Walking on the Cutting Edge of Fashion}

Style features: In the modern minimalist style, lines are simple and smooth, color contrast is strong; a large number of new materials such as tempered glass and stainless steel are used; the emphasis is on the simplicity and functionality; and the emphasis is placed on the singularity and abstractness of the interior space shape and objects.

Suitable plants: thin and tall plants with clear lines and fine leaves or fresh and elegant plants, such as: chlorophytum, 
chrysalidocarpus lutescens, brazilwood, philodendron, mimosa, asparagus fern, queen's bird-of-paradise flower, etc., create a personalized, fresh and elegant modern lifestyle combined with dry branches, dried flowers and relevant utensils.

\section{B. Pastoral Style - Nonchalant and Rustic Romance, the Design Making People Indulge in the Afternoon Flower Shadow and Breeze Under the Vine}

Style features: use rough, broken, natural materials to pursue leisure, comfortable, natural rural life.

Suitable plants: The rural-style indoor plants mainly reflect the pattern and layering of plants and housing structures and decoration styles, achieving harmony and communication between people and nature. Most of these plants are with green leaves and do not bloom. Such as: evergreen, jade hairpin, Africa jasmine, herb flower, chiba wood, malus spectabilis, dracaena draco, scindapsus, pachira macrocarpa, spathiphyllum floribundum, nandina, chrysalidocarpus lutescens, etc.

Mainly divided into English pastoral style and French pastoral style

(1) English pastoral style features: floral, striped, Scottish motifs, gorgeous fabrics and handmade, heavy and intense.

Suitable plants: divergent plants, such as: ivy, sindapsus, etc.; ferns, such as: tuber fern, capillaire, etc.; asteraceae, such as: dahlia pinnata, leucanthemella linearis, etc., create a beautiful, natural landscape.

(2) French pastoral style features: open space, whitewashed furniture, simplified curled corners of the chair legs, exquisite ornamentation, warm and simple colors and simple furniture, there is more natural fresh and Provence romance.

Suitable plants: plants such as asteraceae, fern, commelinaceae, acanthaceae, etc., create a simple, pure and natural style.

\section{Southeast Asian Style - the Weather Is Hot, the Design That Embodies Charming, Gentle and Natural Styles}

Style features: finely crafted Thai style, warm, bright colors, feminine gauze, the enshrouding created by the candle, the scent of incense in the wind, are the expression of the soft and beautiful Southeast Asian style. Wood, rattan, bamboo, and banana are full of tropical exoticism.

Suitable plants: mainly large-leaf plants, foiled by bright flowers. Such as queen's bird-of-paradise flower, traveller'stree, dishgyi, monstera ceriman, alocasia odora, new pteris fern, peony, Chinese herbaceous peony, cuckoo, malus spectabilis, etc., create a warm, unrestrained exotic landscape.

\section{Mediterranean Style - Blue Sky-Like Design}

Style features: sun, beach, beautiful Mediterranean style, there are sunny yellow, white walls, continuous arcades, arches and half arches, horseshoe-like windows and doors, blue Spanish sea-like tables and chairs, Provence purple aroma. The tropical plants with golden, purple flowers and green leaves can make people feel in the Mediterranean air that is full of flower fragrance.

Suitable plants: foliage plants, such as: palm plants; araceae plants; tannia plants; banyan plants of moraceae, as well as lavender, pea-blossom, hyacinths, cornflowers, etc., create cool, romantic feelings in summer.

\section{E. Chinese Style - the Design That Brings Back Nostalgic Thoughts}

Style features: simple and tough straight lines, advocating solemnity and elegance; Chinese traditional pattern embellishment, paying attention to symmetrical beauty; express introverted and simple design effects.

Suitable plants: For Chinese-style ornamental plants, Chinese people pay attention to "viewing their leaves, appreciating their shapes", poetic and picturesque Chinese native plants such as: China blue, kaffir lily, asparagus fern, diospyros armata, club, etc., create connotation and charm.

\section{F. European Style - the Design of Strongly Expressing Traditional Cultures in European Countries}

Style features: the use of pillars, arches, and domes, gorgeous, exaggerated carvings, huge-scale zenith murals and gold-plated, plaster lines and marble materials, reflect the noble, luxurious, magnificent style.

Suitable plants: ornamental flowers such as: transvaal daisy, rosebush, rose, lily, sunflower, etc., pursuit the elegant luxury, the gorgeous space is suitable for flowers.

\section{G. Japanese Style - the Design That Enables People to Enjoy Leisure}

Style features: traditional tatami, logs, white walls and paper, wooden lattice, sliding doors, etc., create a low-profile, simple, neat, natural interior space.

Suitable plants: pine, cypress, bamboo, creates a quiet, distant interior landscape.

\section{H. Fashion Mixed Style - the Design Loved by Salariat}

Style features: diversified design elements, inclusive. The decoration and furnishings integrate ancient and modern, Chinese and foreign features. Such as: traditional screens, modern style walls, doors and windows, European classical lamps, traditional furniture and personalized furnishings. Study deeply the overall composition and visual effects in the shape, color, material and other aspects.

Suitable plants: integrated plant configurations. Such as: large leaves and small leaves, high and low plants, flowers in all kinds of colors, create a characteristic indoor landscape.

\section{CONCLUSION}

With the enrichment of interior design styles, the design of indoor plant landscapes is also becoming rich and varied. In the interior space, designers can put a variety of plants through ingenious design and reasonable layout, and they can combine stone, water, element construction, lighting, natural lighting, 
etc. to perfectly integrate the plants with the interior design style, creating healthy, natural, humanistic interior landscapes where buildings, people and nature can be in harmony.

The indoor plant landscape design is a continuation of the natural environment and a re-creation of interior design. Each of us has the potential to be a creative designer. For our health, for the goal of having a beautiful living environment, let us work hard together!

\section{REFERENCES}

[1] Yang Zimo. "138 kinds of indoor plants that are good for our health", Harbin Publishing House. 《有益健康的 138 种室内植物》杨紫陌编 著, 哈尔滨出版社

[2] Lu Sicong, Lu Wei, Zhu Chongsheng, He Zengming. "Indoor Ornamental Plants - Decoration and Maintenance Appreciation", , China Forestry Publishing House 室内观赏植物一 装饰 - 养护欣赏》 卢思聪, 卢炜, 朱崇胜, 何增明编著 中国林业出版社

[3] Liu Yan. "Garden and Flower Science", China Forestry Publishing House《园林花卉学》刘燕编著, 中国林业出版社

[4] Wu Fanglin, He Xiaotang. "Indoor Plants and Landscape Making", China Forestry Publishing House 《室内植物与景观制造》吴方林, 何 小唐编著. 中国林业出版社

[5] Su Xuehen. "Plant Landscape Planning and Design", China Forestry Publishing House 《植物景观规划设计》苏雪痕主编, 中国林业出版 社

[6] "Green Book of Landscape Design", edited by Hong Kong Rihan International Culture Co., Ltd., China Forestry Publishing House 《景观 设计绿皮书》香港日瀚国际文化有限公司编, 中国林业出版社

[7] Wang Xiaojun. "Landscape Design”, Jiangsu Science and Technology Press. 《风景园林设计》王晓俊 编著 江苏科学技术出版社

[8] Lin Jiayang. "Landscape Design and Training”, China Publishing Group, Oriental Publishing Center《园林设计与实训》林家阳, 主编, 中国出 版集团, 东方出版中心

[9] Hu Changlong. "Plants and indoor air purification", Mechanical Industry Press 《植物与室内空气净化》 胡长龙 编著, 机械工业出 版社 